In $1000 \mathrm{cc}$. chloroform there are

$$
\frac{1000}{\text { II9 }} \text {. I.52 gram-molecules, }
$$

and hence for chloroform we have

$$
\pi=\frac{22222}{1000} \cdot \frac{298}{273} \cdot 0.76 \frac{1000}{\text { II }} \cdot 1 \cdot 52=235 \mathrm{~m} .
$$

In $1000 \mathrm{cc}$. toluene there are

$$
\frac{\text { IO00 }}{9^{2}} \cdot 0.88 \text { gram-molecules, }
$$

and hence for toluene we have

$$
\pi=\frac{22222}{1000} \cdot \frac{298}{273} \cdot 0.76 \frac{1000}{92} \cdot 0.88=176 \mathrm{~m} .
$$

Rutgers College.

[CONTRTBUTIONS FROM THE LABORATORIES OF THE School OF MiNing, KINGSTON, ONTARIO.]

\title{
VOLUMETRIC ESTIMATION OF LEAD.
}

BY FRED. J. POPE.

Received May 2r, 1896.

UITE frequently of late, the attention of readers of chemical journals has been directed to various methods ${ }^{1}$ for estimating lead volumetrically. But, while some of these methods are superior to any previously made public, yet, for none of them is that degree of accuracy claimed which is so essential in a reliable quantitative operation. The chief objection to all of these methods is the use of an outside indicator. However, by using an inside indicator and modifying slightly the usual preliminary steps (necessary for the conversion of the ore into the sulphate) results have been obtained by the writer which are quite satisfactory.

The operation may be briefly outlined as follows: The lead is first converted into lead sulphate, then into lead acetate. Excess of standard potassium bichromate is added, which precipitates the lead as lead chromate. The unused potassium bichromate is reduced by excess of standard arsenious acid, and this latter

1 This Journal, 17, 901; Engineering and Mining Journal, July 7, 1894. 
titrated with iodine solution, using starch paste as an indicator.

PREPARATION AND STANDARDIZING OF SOLCTIONS.

Taking tenth normal solution of iodine as the standard, 4.995 grams of arsenious acid per liter and 4.763 grams of potassium bichromate per liter give standard solutions of equivalent value per equal volumes.

Iodine.-I2.7 grams are dissolved in concentrated potassium iodide solution and made up to one liter.

Arsenious Acid.-Dissolve 4.95 grams in twenty or thirty cc. of saturated, filtered solution of sodium carbonate, gently warming. If too strong heat is applied the arsenious acid cakes and dissolves with difficulty.

By means of a burette accurately measure ten to fifteen cc. of arsenious acid solution, running it into a large porcelain dish. Acidify faintly with sulphuric acid, add fifty cc. saturated solution of pure sodium bicarbonate, add starch paste and titrate with the iodine.

Potassizm Bichromate. - Weigh out approximately five grams, dissolve and make up to one liter. Remove twenty-five cc. to a porcelain dish, add fifty cc. of the standard arsenious acid and proceed with titration as already indicater.

Note.-Since all commercial sodium bicarbonate will decolorize more or less iodine, it is well in neutralizing to get the neutral point exactly. When this is attained, add fifty cc. sodium bicarbonate and deduct its iodine value from the quantity consumed.

The Operation in Detail.-Take from three to seven grams of ore, according to its richness in lead. Place this in a deep three-inch porcelain dish, thoroughly moisten it with water, cover the dish with a watch-glass and for each gram of ore used add four to five cc. of a previously prepared mixture of two parts by volume of sulphuric acid, three parts by volume of nitric acid and one part by volume of water. When the reaction, which first results, diminishes, evaporate as nearly to dryness as is possible without spurting. Cool, fill the dish with cold water, stir well and allow to settle for two or three minutes. Filter and wash with cold water until most of the acid is removed. Convey the 
filter paper with the precipitate to a 300 to $400 \mathrm{cc}$. beaker or Erlenmeyer flask and neutralize any remaining acid with dilute ammonia. To the porcelain dish add ten to fifteen $\mathrm{cc}$. strong ammonium acetate, made decidedly acid with acetic acid. Add an equal volume of water and boil for two or three minutes, washing the sides of dish so as to remove any remaining lead sulphate. This solution is then added to the flask containing the precipitate and the whole boiled from seven to ten minutes with frequent stirring. Cool, neutralize with ammonia, add I00 cc. of standard potassium bichromate, stirring well. Filter into a half liter measuring flask, moistening the filter paper with dilute ammonia or ammonium acetate. Wash precipitate as much as is possible in the flask, using hot water. The filtrate make up to the mark, and for titrating remove $100 \mathrm{cc}$. to a large one and one-half liter porcelain basin. Add ten to twenty cc. (or less if ore is rich in lead) of standard arsenious acid. Make decidedly acid with forty per cent. sulphuric acid and stir until the yellow color disappears or the liquid has a greenish tinge. A large excess of sulphuric acid is to be avoided. Neutralize with saturated solution of sodium bicarbonate and then add an excess of fifty $\mathrm{cc}$. If the solution has a deep greenish tinge dilute it with distilled water. Finally add starch paste and titrate with standard iodine solution.

As a test of the accuracy of method, five portions of pure lead sulphate were acted upon and the following results obtained:

Grams taken.
I.
I.I
I. 2
I. 3
I. 4

$$
\begin{gathered}
\text { Grams found. } \\
\text { I. } 000568 \\
\text { I.099375 } \\
\text { I. } 200467 \\
\text { I.300673 } \\
\text { I.39957 I }
\end{gathered}
$$

With a specimen of galena containing quartz and calcium carbonate, the writer obtained the following percentages:

Grams taken.

0.7

0.7

$0.7 \mathrm{I}$

0.68
Per cent. lead found.

$8 \mathrm{r} .89$

81.96

81.94

$8 \mathrm{I} .90$ 
As a test of the method in the hands of inexperienced operators, it was outlined and explained to four junior students, who with the galena ore already mentioned, obtained the following results :

\begin{tabular}{|c|c|}
\hline Grams taken. & Per cent. lead found. \\
\hline R. $\mathrm{H}=0.7$ & 81.86 \\
\hline G. E. R. $=0.7$ & $8 \mathrm{I} \cdot 78$ \\
\hline S. D. $\{\mathrm{I}=0.7$ & 82.00 \\
\hline$Z_{2}=0.85$ & 8 I. 89 \\
\hline G. E. S $=0.7$ & 8I. 95 \\
\hline
\end{tabular}

With another ore containing five per cent. of copper, twentysix per cent. of iron, quartz and gypsum, one of the students obtained the following results :

Grams taken.

3.0

$3 \cdot 5$

4.0
Per cent. lead found

I 5.89

16.01

I 5.97

\section{ESTIMATION OF SULPHIDES IN CALCIUM CARBIDE.}

BX FRED. J. POPE.

Received May 2I, 1896 .

WEIGHED quantity of calcium carbide was conveyed to $A$ a dry Erlenmeyer flask provided with a stop-cock funnel and a delivery tube, which latter led to a ten ounce wash bottle, this in turn being connected with a smallerone. The wash bottles contained $150 \mathrm{cc}$. lead acetate of known strength (about tenth norma1). By means of a stop-cock water was carefully added until there was nofurther evolution of acetylene. On the reaction ceasing, twenty-five to forty $c c$. sulphuric acid ( $1: 3$ ) was run into the flask and the whole gently boiled, the liberated hydrogen sulphide passing into the wash bottles and precipitating the lead as lead sulphide. When the reaction had ceased the flask and liquid was washed free of hydrogen sulphide by a current of air and the contents of wash bottles filtered. The filtrate containing unconsumed lead acetate was made up to a half liter. To roo $\mathrm{cc}$. of this solution were added standard potassium bichromate, arsenious acid, etc., (as indicated in preceding article) and total amount of unconsumed lead acetate estimated. The difference between this 